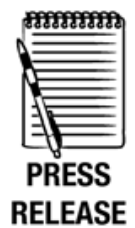

Faculty of Health and Social Sciences, University of Bedfordshire, Luton, UK ${ }^{2}$ Faculty of Social and Health Sciences, Unitec New Zealand, Auckland, New Zealand ${ }^{3}$ Vertical Theme Head Ethics, Professionalism, Leadership and Management, Imperial College, London, UK

${ }^{4}$ National Heart and Lung Institute, Imperial College, London, UK

\section{Correspondence to} Professor Michael

Preston-Shoot, Dean, Faculty of Health and Social Sciences, University of Bedfordshire, Park Square, Luton LU1 3JU,

England, UK; michael. preston-shoot@beds.ac.uk

Received 1 December 2010 Revised 27 January 2011 Accepted 10 March 2011 Published Online First 16 May 2011

\title{
Readiness for legally literate medical practice? Student perceptions of their undergraduate medico-legal education
}

\author{
Michael Preston-Shoot, ${ }^{1}$ Judy McKimm, ${ }^{2}$ Wing May Kong, ${ }^{3}$ Sue Smith ${ }^{4}$
}

\begin{abstract}
Medical councils increasingly require graduates to understand law and to practise medicine mindful of the legal rules. In the UK a revised curriculum for medical law and ethics has been published. However, coverage of law in medical education remains variable and doubts exist about how far students acquire legal knowledge and skills in its implementation. This survey of students in two UK medical schools measured their law learning and their confidence in using this knowledge. Concept maps and a self-audit questionnaire were used to capture students' understanding and perceptions of this knowledge domain and self-assessments of their legal knowledge and skills. A large sample was achieved across first, second and final year students. Students agree that a sound understanding of law is essential to being a good doctor. Their perceptions of law are generally positive but the interface between the legal rules and codes of medical ethics creates difficulty. In some areas students offer relatively confident selfassessments of their legal knowledge and skills for practising law. However, levels of confidence in other areas of their law learning raise doubts about the degree to which they can advocate for and protect their patients. Conclusions are drawn about the effectiveness of students' law learning and recommendations made for further research.
\end{abstract}

\section{INTRODUCTION}

Good medical practice requires that medical undergraduates can demonstrate in practice knowledge and understanding of the law. ${ }^{1-5} \mathrm{~A}$ detailed, revised law curriculum ${ }^{6}$ has been produced for use in UK medical schools. However, a recent systematic literature review ${ }^{7}$ has identified variability within medico-legal curriculum content, limited time allocated to law learning and its relative neglect in clinical rotations. Students and practising doctors reported widespread deficiencies in knowledge and understanding of legal rules. ${ }^{7-10}$

A recent survey of UK medical schools ${ }^{11}$ found varied coverage of recommended topics, and that teaching, learning and assessment of law in clinical attachments is much less developed than that in non-clinical education. This may partly explain why students report feeling inadequately prepared for the medico-legal aspects of practice. ${ }^{12-15}$ Students are positive about law teaching, valuing its relevance for their future practice. However, they are also concerned that their legal education can be eroded in practice by their clinical teachers ${ }^{16} 17$ and that they lack confidence in their ability to challenge established practices, even when convinced of their knowledge of ethics and law. ${ }^{18}$ A greater focus on law in clinical practice, rather than learning in the abstract, appears necessary to facilitate knowledge and skill retention and development.

If future doctors are to uphold and advocate effectively for the legal rights of patients they must have a sound grasp of the law and the confidence to apply that understanding. In this context, medical students from two UK universities were asked to evaluate their knowledge and understanding of medico-legal rules and their perception of the law.

\section{METHODS}

Using a cross sectional design, first and second year students were surveyed, the former before any formal law and ethics teaching had taken place. Final year students were surveyed shortly before graduation. Ethical approval was obtained from participating universities and informed consent was obtained from participating students.

Those participating completed a self-audit questionnaire and a concept map in which students were asked individually to generate words or phrases associated with the trigger caption 'law and medicine' prior to completing the survey questionnaire. The researchers developed the self audit with five law teachers from different medical programmes to ensure internal reliability and content validity. It covers both essential core content ${ }^{1}{ }^{6}$ and other topics covered by some programmes. ${ }^{11}$ Essentially it is a self-efficacy scale, that is, a tool designed to provide an estimate of an individual's belief in their ability to meet a particular target or goal. As such, it provides a measure of the effectiveness of law teaching in fostering student self-confidence and thus may predict future behaviour since students who feel secure in their knowledge and confident in their ability are likely to be more effective practitioners. ${ }^{19}$ Three domains were covered using a 4 point Likert Scale:

- Perception of lawyers and of the law (16 statements);

- Skills for practising law in relation to medicine (18 statements);

- Knowledge of legal powers, duties and case law (41 statements).

A positive relationship was hypothesised between students' year of study, perceptions of law relating to medicine and degree of confidence in their knowledge and skills. To test this, the Likert Scale percentages were added together. A series of $2 \times 2$, students' self-assessment versus study level 
contingency tables were then produced, using SPSS V.17, and $\chi^{2}$ statistical tests calculated. A Fisher's Exact Test was used, providing an exact rather than estimated $p$ value. ${ }^{20}$

The concept map was designed to generate perceptions of law in medical practice. Concept maps can indicate students' understanding of a knowledge domain and assess and provide feedback about their learning. ${ }^{21} 22$ Data were entered into Excel and analysed using NVivo V.7 software and independent thematic evaluation by the researchers.

In all, 1154 undergraduate medical students participated from first (543), second (279) and final year (332) cohorts on one 6 year MBBS/BSc programme (School A) and a 5 year $\mathrm{MBBS}$ and 4 year graduate entry MBBS (School B). More final year students responded from School A; more first and second year students from School B. The overall student response rate was $46 \%$. However, this conceals considerable variation between schools and between years. For example, first year cohorts from School A yielded an 87\% response rate in 2007 but only a $32 \%$ response rate the following year, while in School B the equivalent first year response rates were $26 \%$ and $52 \%$. Both schools taught law alongside medical ethics, the major input coming at the end of year one or during year two, covering consent, capacity, confidentiality, negligence and child protection. This teaching was formally assessed. Specialist, sometimes optional, inputs were available later, including mental health and childcare law.

\section{RESULTS}

Results here have been aggregated for analysis since the percentage response rate did not have any significant impact on the pattern of answers given.

\section{Perception of law and lawyers}

Table 1 summarises students' perceptions according to year of study. A sound understanding of law is seen as essential by the great majority of students, enabling doctors to achieve health improvements, protect vulnerable people and demonstrate accountability. Overall, positive perceptions of the law tend to increase and negative perceptions to decrease between the early years and final year. However, concerns persist about defensive practice, keeping updated, the synergy between law and medical values, and applying legal rules. Arguably, considering the percentages in the table, most perceptions change little as a result of teaching.

The relationship between level of study and perceptions of medico-legal questions was statistically significant (at $p<0.001)$ in only three areas:

- Law is unsuitable for resolving for resolving health/medical issues (decreases with time);

- A sound understanding of law is essential to being a good doctor (increases with time);

- Law encourages defensive practice (increases with time).

Overall, this would suggest that students' perceptions of the value of law to doctors and patients become more positive with time.

\section{Skills for practising law in medicine}

Table 2 highlights the levels of undergraduate confidence in their medico-legal skills. The relationship between level of study and degree of confidence in skills in applying medico-legal rules was statistically significant in five areas, as indicated, although not always in the direction of acquiring greater confidence.

Overall, students are not very self-confident. In no case did more than $4 \%$ of students in any cohort feel 'very confident' in a legal skill. As might be anticipated, there is a reported increase in confidence between first, second year and final year students in some items. With other skills, however, students appear to become less confident over time. Perhaps this signifies a realisation of what they do not know. Alternatively perhaps as they gain life and clinical experience (learning that life is often complex and decision making may require shades of grey), they see issues as more complex and thus have less confidence in decision making. It may be significant that the area in which students report the greatest levels of confidence, that of working in partnership with patients, service users and carers, is arguably one which has closer associations with values and ethics than with law and legal practice.

Table 1 Medical student perceptions of law over time

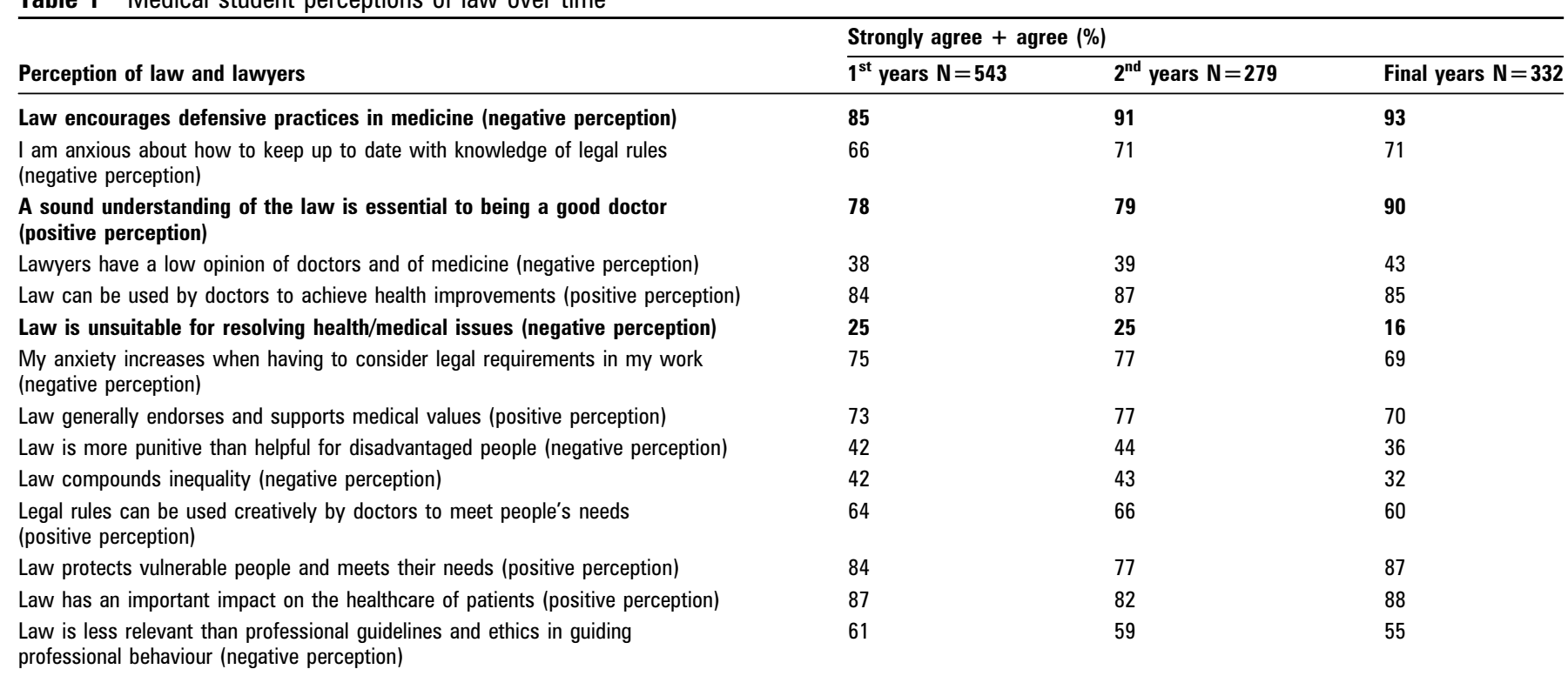

Perceptions which changed statistically significantly over time are shown in bold. 
Table 2 Reported degrees of confidence relating to skills for practising law in relation to medicine

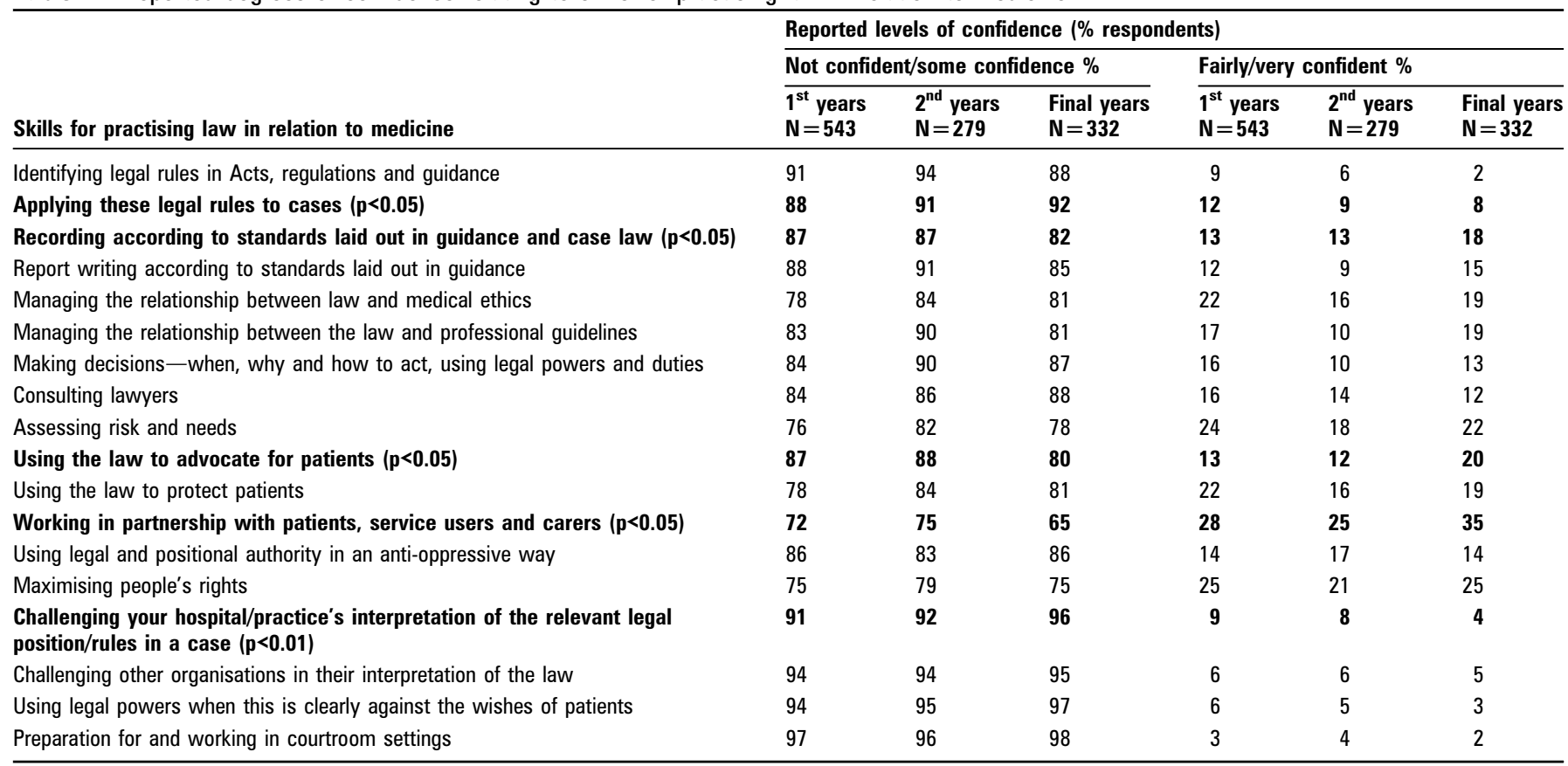

Perceptions which changed statistically significantly over time are shown in bold.

Self-reported knowledge of legal powers, duties and case law Table 3 identifies self-reported levels of knowledge. To highlight important strengths and weaknesses in current law teaching, the table first presents core content areas $^{1}$ and then supplementary useful knowledge for qualifying doctors. In some areas there is a significant relationship between level of study and self-reported degree of confident knowledge of medico-legal rules (indicated in bold) although again this is not always in the direction of students acquiring greater understanding by graduation.

In no case did more than $13 \%$ of students in any cohort report feeling 'very confident' in their legal knowledge, perhaps partly because, at this stage in their careers, it may be difficult for medical students to judge how much legal knowledge they will require. If all confidence reports (little, reasonably, fully) are combined, there is a marked increase in reported knowledge between the first and final year for some topics (box 1). More modest rises in confidence are found elsewhere. These perceived strengths appear partly related to the emphases given in teaching law. In three knowledge areas, students reported feeling less confident as they progress through their programmes: race relations, community care assessment and domestic violence legislation.

\section{Concept mapping}

Thematic analysis generated core themes derived from individual words or phrases to produce a 'profile' of how medical students perceive the law in relation to medical practice. Statistically significant (at $\mathrm{p}<0.001) \quad \chi^{2}$ Fisher's Exact Test findings are noted.

Final year students use a wider range of words, with more complex connections, to describe the law. Ethico-legal matters relating to medicine are consistently highlighted. Mirroring the self audit, law is associated with defensive practice and litigation. The wider societal and political context is little acknowledged. However, more final year students than first years include legal terms applied to medicine (28\% final year compared to $15 \%$ first year; $\mathrm{p}<0.001)$, the role of the doctor and professional identity $(16 \%$ final years, $9 \%$ first year), problems encountered by patients $(13 \%$ final year, $2 \%$ first year; $p<0.001)$ and patient populations $(12 \%$ final years, $2 \%$ first year; $p<0.001)$. A shift appears, with final year students seeing the law in broader terms around patient populations, their problems and the role of the doctor. The following broad themes were identified:

- Theme 1: legislative governmental structures. Final year students cited more words overall here than first years, with red tape (31\% final year compared to $10 \%$ first year; $p<0.001)$ and politics $(21 \%$ final year, $10 \%$ first year; $p<0.001)$ most prominent.

- Theme 2: law within an organisational context. Both first and final year students showed awareness of a range of organisations. The agency cited most often by both groups was the Medical Defence Union (30\% final year, $42 \%$ first year; $\mathrm{p}<0.001)$. The Medical Protection Society was cited by $35 \%$ of final years compared to $4 \%$ of first years $(p<0.001)$.

- Theme 3: legal terminology, such as acts, parental responsibility, duty of care and terms concerned with litigation against doctors. Both year groups used a wide range of terms but most of these were cited by less than $5 \%$ of the respondents. Final year students cited more terms overall. 'Litigation' (22\% final year, $7 \%$ first year; $p<0.001$ ) and 'being sued' (17\% final years, $12 \%$ first year; $p<0.001)$ figured most prominently.

- Theme 4: medical ethico-legal matters. Both first and final year students consistently highlighted ethical terms including 'confidentiality' (27\% final year compared to $21 \%$ first year), 'euthanasia' (14\% final year, 19\% first year) and 'abortion' (11\% final year, $19 \%$ first year; $p<0.01)$. Final year students also referred to 'do not resuscitate' notices (7\% final year, $1 \%$ first year; $p<0.001)$ and 'sectioning' $(6 \%$ final year, $0 \%$ first year; $\mathrm{p}<0.001)$.

- Theme 5: legal terms applied to medicine. Both groups cited a range of terms including 'patient consent' (25\% final year compared to $20 \%$ first year); 'GMC guidelines' (17\% final 
Table 3 Students' \% responses relating to their perceived knowledge of legal powers, duties and care law

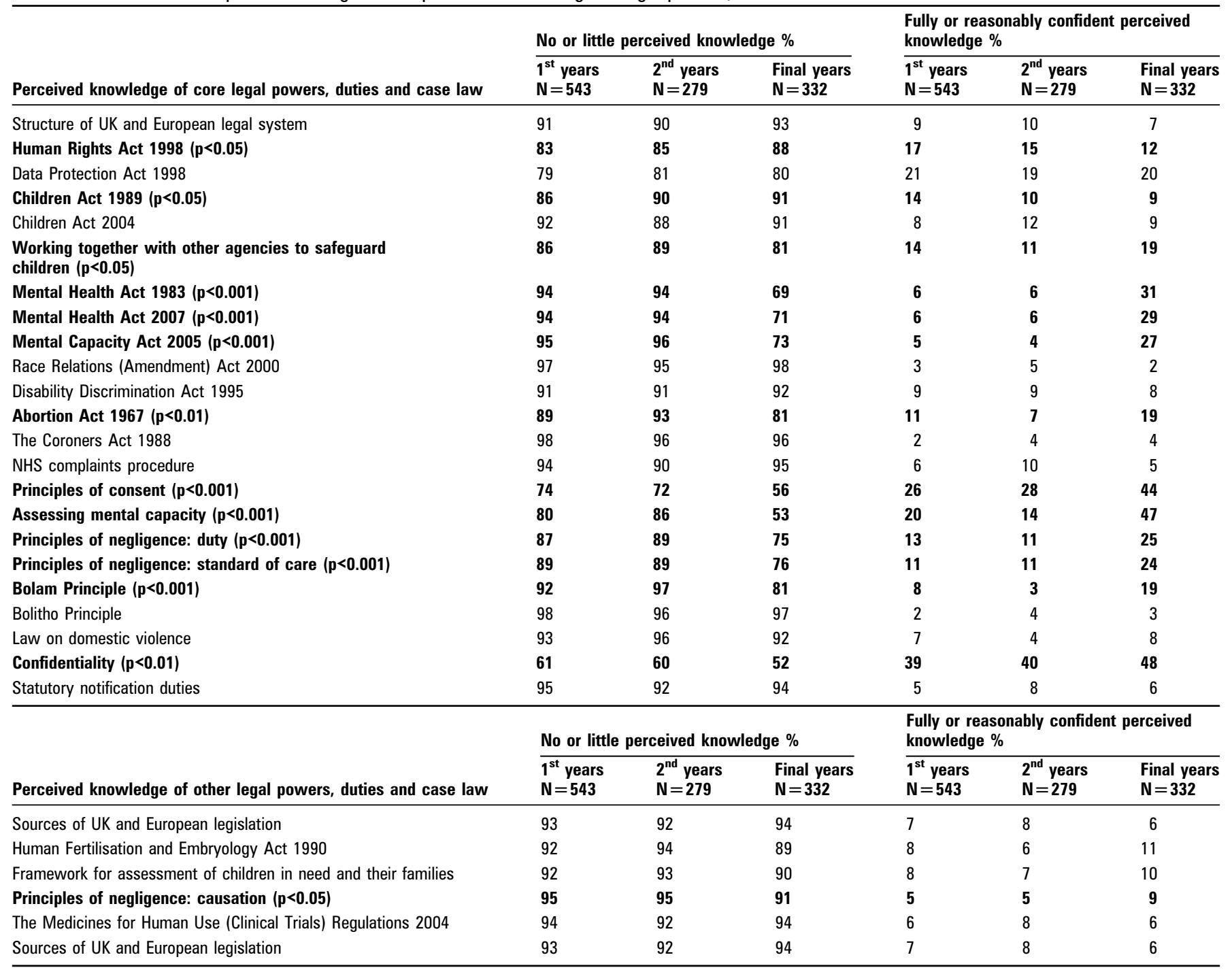

Perceptions which changed statistically significantly over time are shown in bold.

year, $12 \%$ first year) and 'negligence' (16\% final year, $6 \%$ first year; $\mathrm{p}<0.001)$. First year students were more likely to cite the 'rights of patients' ( $6 \%$ of final years compared to $11 \%$ of first years; $p<0.001)$ and 'malpractice' ( $5 \%$ of final years compared to $11 \%$ of first years; $\mathrm{p}<0.001)$.

- Theme 6: doctors' roles and responsibilities, such as decision making and accountability, alongside areas of activity and patient groups, including advocacy and care homes. Attributes and professional values, also emerge, for example, 'trust', 'compassion' and 'integrity'. A wide range of terms were cited by both year groups but mostly by less than $5 \%$ of respondents. Only two terms were cited by more than $20 \%$ of respondents, namely 'protection' (37\% final year, 19\% first year; $p<0.001)$ and 'documentation' (21\% final year, $2 \%$ first year; $p<0.001$ ).

- Theme 7: what law means in practice. Law might control or restrict practice, prove complex, empower staff and patients, mandate partnership working or promote equality. However, most terms were cited by less than $5 \%$ of respondents. Only two were referred to by more than $20 \%$ of students, 'competence' (61\% final year, $20 \%$ first year; $\mathrm{p}<0.001)$ and 'best interests' (22\% final year, 18\% first year).
- Theme 8: positive and negative feelings about the law. Strikingly, most terms cited by both groups were negative. Although law is seen as 'necessary' (16\% final year, 9\% first year) and 'changing' (16\% final year, $13 \%$ first year), it is also prompts associations with 'risk' (33\% final year, 16\% first year; $p<0.001)$ and 'stress' (33\% final year, 12\% first year; $\mathrm{p}<0.001$ ). Twenty per cent of first year students but no final year student saw the law as about 'manipulation'. That legal issues could bring exposure is implied by reference to 'publicity' (12\% final year, 9\% first year).

- Theme 9: patient populations (including generalised descriptors such as vulnerability and ethnicity). Those most often cited were 'children at risk' (44\% final year, 20\% first year, $\mathrm{p}<0.001)$, 'disabled people' $(12 \%$ final year students, $16 \%$ first year), 'older people' (15\% final year, $10 \%$ first year) and 'vulnerable people' (13\% final year, 9\% first year).

- Theme 10: problems encountered by doctors, including cultural issues and discriminatory attitudes. The law may be seen as affecting and possibly restricting practice, for example, through directives about hours of work. First year students cited a wider range of problems. 'Safety' was cited by $31 \%$ of final years and $5 \%$ of first years $(p<0.001)$; 
Box 1 Self-reported levels of confidence in legal knowledge

Marked increase in confidence, statistically significant

- Assessing mental capacity (from $47 \%$ to $93 \% ; p<0.001$ )

- Mental Capacity Act 2005 (from 32\% to 92\%; $p<0.001$ )

- Mental Health Act 1983 (from 31\% to $90 \% ; p<0.001$ ) and 2007 (from 39\% to $92 \% ; p<0.001$ )

- Principles of consent (from $55 \%$ to $85 \% ; p<0.001$ )

- Working together with other agencies to safeguard children (from $58 \%$ to $84 \% ; p<0.001$ )

- Abortion Act 1967 (from $50 \%$ to $73 \% ; p<0.001$ )

- Principles of negligence: standard of care (from $40 \%$ to $73 \%$; $\mathrm{p}<0.001)$

- Principles of negligence: duty (from $35 \%$ to $72 \% ; p<0.001$ )

- Children Act 1989 (from 45\% to 67\%; $p<0.001$ )

- Human Fertilisation and Embryology Act 1990 (from 42\% to $64 \% ; p<0.001)$

- Bolam Principle (from $12 \%$ to $56 \% ; \mathrm{p}<0.001$ )

- Principles of negligence: causation (from $24 \%$ to $45 \%$; $p<0.001$ )

Modest, but statistically significant, increase in confidence

- Disability Discrimination Act 1995 (from $48 \%$ to $65 \%$; $\mathrm{p}<0.001$ )

- Statutory Notification Duties (from $30 \%$ to $46 \% ; p<0.001$ )

- The Coroners Act 1988 (from $16 \%$ to $36 \% ; p<0.001$ )

'mistakes' by $2 \%$ of final years and $12 \%$ of first years $(\mathrm{p}<0.001)$; 'conflict' by $11 \%$ of final years and $10 \%$ of first years, and the 'EU working time directive' by $10 \%$ of final years and $6 \%$ of first years.

- Theme 11: professional groups. Although 'doctors' $(27 \%$ final year, 54\% first year; $\mathrm{p}<0.001$ ), 'GPs' ( $8 \%$ final year, $16 \%$ first year; $p<0.001$ ), and 'nurses' ( $8 \%$ final years, $17 \%$ first year; $p<0.001$ ) were cited by both groups, $60 \%$ of final year students cited 'social workers' compared to only $13 \%$ of first year students $(p<0.001)$.

- Theme 12: criminal matters, including such legal terminology as prosecution, processes like sentencing and criminal record checks, and offences of abuse, assault, harassment and theft. 'Abuse' was cited by $52 \%$ of final year students and $20 \%$ of first years $(p<0.001)$; 'drug abuse' by $11 \%$ of final years and $5 \%$ of first years $(p<0.001)$ and 'battery' by $12 \%$ of final years and $2 \%$ of first years $(p<0.001)$. Around $10 \%$ of first year students referred to 'criminal', 'prosecution', and 'right and wrong'

- Theme 13: Financial matters negative descriptors are prominent, for example, 'costs' and 'fees'. Law was described primarily in terms of 'money' (61\% final year, 50\% first year; $\mathrm{p}<0.001)$ and 'funding' (22\% final year, $27 \%$ first year).

- Theme 14: structures and processes surrounding medicolegal training. Law and medicine was described primarily in terms of 'knowledge' (37\% final year, 28\% first year), 'education' (31\% final year, 10\% first year; $p<0.001)$ and 'research' (15\% final year, 21\% first year). First year students also referred to 'professional development', 'qualifications' and 'cheating'.

- Theme 15: specific presenting problems where doctors need an understanding of the law to help patients. 'mental health/capacity' was cited by $90 \%$ of final year and $33 \%$ of first year students $(p<0.001)$. 'Treatment' was cited by $2 \%$ of final year students but $20 \%$ of first years $(p<0.001)$.

\section{DISCUSSION}

This research explored students' evaluation of their law learning across cognitive (knowledge organisation), skills and affective (perceptions and self-efficacy) dimensions. ${ }^{23} 24$ Using one benchmark for medical education research, ${ }^{25}$ this study enabled comparisons across two institutions and several stages of education, using a large sample. The data collection methods allowed analysis of the statistical power of the findings. Although there were considerable variations in the proportions of students choosing to participate between years and between schools, there was no evidence that this variable response rate had any impact on the responses given. Students were not responding to insider researchers, staff involved in their professional education, which may have encouraged more open and critical reflections.

However, the study relied on self-reporting rather than triangulating student self-assessment with tutor ratings, assessment outcomes, scrutiny of course documentation and/or interviews. Including student interviews would have enabled potential drawbacks of self-efficacy scales to be addressed through exploration of the meanings attributed to the questions and of the likely impact of the clinical context on their use of knowledge and skills. Similarly, interviews, alongside assessment outcomes, could have explored their engagement with concept mapping, the degree to which their maps captured and disclosed all that they had learnt, and the contribution of external verification to the measurement of meaning. ${ }^{2627}$ Scrutiny of course documentation, for example, for the orientations taken to the relationship between law, values, rights and practice, coupled with tutor interviews to discuss the context in which students learn about the legal rules and the emphasis given to particular knowledge fields, might help to explain some of the differences discovered across the two medical schools.

Equally, while it might be desirable to relate self-assessed confidence levels with outcome measures of assessment, in practice it is difficult to attempt a direct comparison of performance in two medical schools. Although both curricula met the minimum requirements laid down by Tomorrow's Doctors, ${ }^{1}$ they vary in the sequence of delivery, the way in which content is delivered and assessed, the fine detail of content and potentially the degree to which they exceed the minimum standards required. Although law curricula remained unchanged during the study, this cross sectional research took a snapshot of students over two academic years rather than followed each cohort longitudinally to test the relationship between teaching and confident use of knowledge and skills. The primary focus of our study was to explore students' self-confidence and perceptions of law. Thus, responses in the self audit depend on what level of knowledge students feel they should have to be confident. Interestingly, there were some areas in which confidence fell with training, perhaps because students knew more and were consequently more aware of what they didn't know. Equally, framing the knowledge audit around specific legislative acts rather than points of law, such as the basis of decision making for children, may have perturbed respondents. Arguably, understanding how the law should be applied in clinical practice is at least as as important as familiarity with the technical details of specific legislation. Finally, as students were not followed into postgraduate practice, the impact of teaching and learning on subsequent experience was not explored. 
How prepared are medical students for the legal aspects of their future practice? Medical students' perception of law is generally positive, recognising its role in protecting patients and improving healthcare standards. However, some negative images surface, for instance surrounding defensive practice, litigation and whether the law supports medical values, often increasing as degree programmes progress. This may suggest that the hidden curriculum ${ }^{6}$ is dominant in later training stages. When senior doctors' attitudes are less positive about the law, ${ }^{7} 1018$ students may be less inclined to engage with it as a way of protecting and empowering patients. They have some confidence in a range of skills but express anxiety about using legal rules and about challenging observed deficiencies in practice. The similarity of student responses from two distinctive institutions with different undergraduate programmes and structures for law teaching might also suggest that much learning is part of the hidden curriculum, embedded within broader aspects of medical culture and practice.

Certain areas of the core content of law learning ${ }^{16}$ appear to be clearly understood by a majority of students, including mental health, consent to treatment and confidentiality where there is a positive increase in confidence from first to final years in the knowledge base. Confidence levels about the Coroner's Act and about working in court room settings were generally low, yet, once qualified, knowledge and skill will be needed here. This low confidence could reflect the small amount of time devoted to this in the curriculum or could relate to a more generalised anxiety about the possibility of working in an environment which 'belongs' to another set of professionals. More students were confident about the legal principles of negligence than the NHS complaints procedure. However, in practice, complaints are much more common than negligence cases, suggesting that the focus of teaching in this area may benefit from a change of emphasis. There are some topics, such as the Bolitho principle, domestic violence and race relations, which are very relevant to foundation year practice but for which final year students expressed very low levels of confidence. More explicit teaching here would support the later clinical years of undergraduate training and might enable students to see beyond litigation to potentially empowering uses of the law.

In many areas, only modest differences were found between first, second and final year responses, whether or not students had pre-existing knowledge. In only one skill, working in partnership with patients, did more than one-third of students feel reasonably or fully confident before graduating, and in only three knowledge areas: principles of consent, assessing mental capacity and confidentiality. This may reflect the findings from a practice survey ${ }^{11}$ which reported that most law teaching occurs in the early years of UK undergraduate programmes, with teaching and learning of law in clinical attachments later in the course being relatively less formalised. Together with the limited expressions of full confidence, the findings from this study suggest that academic and practice learning opportunities may have variable or little impact on confidence. The time devoted to law, in the classroom and in practice, may well be insufficient to embed legal literacy and be incommensurate with its importance. ${ }^{7}$ Alternatively, it could reflect the influence of the hidden curriculum, which does not adequately reinforce the importance of the law to clinical practice, or students may feel that they need to know relatively little law to pass their final examinations or to practice in their Foundation posts, and therefore devote less time to consolidating this topic than to other elements of the curriculum. This matters, because in many areas of medical practice doctors should know and be able to draw upon underpinning legal rules. Additionally, if already practising clinicians do not know the legal rules surrounding their specialist fields, ${ }^{8} 1317$ it is unclear from where emerging graduates will learn to apply their theoretical knowledge of the law. Equally, if medical graduates do not know what they do not know and/or where to find it, they will be less able to advocate for and protect patients, or work effectively within the law themselves as practitioners.

The strong link with ethics reflects the dominant ethico-legal stance taken in teaching. ${ }^{7}{ }^{11}$ However, law remains more implicit than explicit. Medical students may have a broad understanding of law surrounding ethical dilemmas but be less able to articulate how legal rules might shape and drive professional practice. This may prove problematic when the law, professional guidelines and ethical codes diverge in their response to dilemmas and specifications for good patient care. The increased emphasis on 'professionalism', as required by statutory and professional bodies, offers opportunities for curricula to include a consideration of law. The development of 'professionalism' and 'professional identity' needs to consider a student/doctor's understanding of, and orientation towards the law. Not all students will see the law in the same way.

Medical students are not alone in finding the law difficult to understand or implement, for instance relating to information sharing and human rights, assessment of mental capacity and keeping up-to-date. ${ }^{28-30}$ This further underscores the importance of structured law teaching throughout qualifying programmes, and law learning in clinical attachments and continuing professional development. ${ }^{711}$ Otherwise, knowledge and skills, even when acquired, may decay.

On working inter-professionally with lawyers and other professionals, the findings are double-edged. Medical students become more optimistic about their standing with legal practitioners but less confident about consulting lawyers and working in courts. This finding mirrors other studies. ${ }^{7}$ It reinforces the importance of continuing professional development to enhance doctors' confidence in engaging when necessary with the legal system. Evidence of diminishing confidence in challenging observed practice echoes other research findings ${ }^{13} 1831$ on the hidden curriculum. Acknowledging incidents of institutional abuse in health and social care, law learning must help medical practitioners to resist becoming acculturated to organisational procedures and colleagues' poor performance and behaviour which expose patients to harm.

This study has shown that it is possible to explore student responses to law learning in medical education. Research that follows individual students and their cohorts through and beyond undergraduate medical education, and that also explores which teaching and assessment methods they find useful, will add to the quality of the evidence base. This study shows that the majority of students lack confidence in their knowledge and skills across many areas of medical law. This suggests that in their clinical training greater attention and time should be given to the practical application of legal knowledge. If young doctors do not feel confident, they are unlikely to challenge poor practice or show leadership in promoting better patient care through using legal rules and an understanding of how law relates to and underpins good medical practice.

Acknowledgements Professor Stewart Peterson (University of Leicester) and Isabella McMurray (University of Bedfordshire).

Funding The study was part funded by a National Teaching Fellowship awarded to the first author by the Higher Education Academy. 


\section{Competing interests None.}

Ethics approval This study was conducted with the approval of the University of Bedfordshire Research Ethics Committee.

Contributors The authors participated in the design and completion of the study and writing of the paper.

Provenance and peer review Not commissioned; externally peer reviewed.

\section{REFERENCES}

1. General Medical Council. Tomorrow's Doctors. Outcomes and Standards for Undergraduate Medical Education. London: GMC, 2009.

2. Bloch R, Bürgi H. The Swiss catalogue of learning objectives. Med Teach 2002:24:144-50

3. Medical Council of Canada. Objectives for the Qualifying Examination. 3rd edn. Ottawa: Medical Council of Canada, 2003.

4. Australian Medical Council. Assessment and Accreditation of Medical Schools: Standards and Procedures. Kingston, ACT: AMC, 2009.

5. Core Committee, Institute for International Medical Education. Global minimum essential requirements in medical education. Med Teach 2002;24:130-5

6. Stirrat G, Johnston C, Gillon R, et al. Medical ethics and law for doctors of tomorrow: the 1998 Consensus Statement updated. J Med Ethics 2010;36:55-60.

7. Preston-Shoot M, McKimm J. Towards effective outcomes in teaching, learning and assessment of law in medical education. Med Educ 2011:45:339-46.

8. Saltstone S, Saltstone R, Rowe B. Knowledge of medical-legal issues. Survey of Ontario family medicine residents. Can Fam Physician 1997;43:669-73.

9. Johnston C, Haughton P. Medical students' perceptions of their ethics teaching. $J$ Med Ethics 2007;33:418-22.

10. Elger B, Harding T. Avoidable breaches of confidentiality: a study among students of medicine and of law. Med Educ 2005;39:333-7.

11. Preston-Shoot M, McKimm J. Prepared for practice? Law teaching and assessment in UK medical schools. J Med Ethics 2010;36:694-9.

12. Furman C, Head B, Lazor B, et al. Evaluation of an educational intervention to encourage advance directive discussions between medicine residents and patients. J Palliat Med 2006;9:964-7.

13. Hariharan S, Jonnalagadda $\mathrm{R}$, Walrond $\mathrm{E}$, et al. Knowledge, attitudes and practice of healthcare ethics and law among doctors and nurses in Barbados. BMC Med Ethics 2006:7:E7.

14. Gome $\mathbf{J}$, Paltridge D, Inder W. Review of intern preparedness and education experiences in general medicine. Intern Med J 2008;38:249-53.
15. Knight B, Thompson I. The teaching of legal medicine in British medical schools. Med Educ 1986;20:246-58.

16. Alpert $\mathbf{E}$, Tonkin A, Maizel Seeherman A, et al. Family violence curricula in US medical schools. Am J Prev Med 1998:14:273-82.

17. Schildmann J, Cushing A, Doyal L, et al. Informed consent in clinical practice: pre-registration house officers' knowledge, difficulties and the need for postgraduate training. Med Teach 2005;27:649-51.

18. Cordingley L, Hyde C, Peters S, et al. Undergraduate medical students' exposure to clinical ethics: a challenge to the development of professional behaviours? Med Educ 2007:41:1202-9

19. Quinney A, Parker J. Developing self efficacy in research skills: becoming researchminded. In: Burgess H, Carpenter J, eds. The Outcomes of Social Work Education: Developing Evaluation Methods. Southampton: Higher Education Academy Subject Centre for Social Policy and Social Work, 2010

20. Hinton P, Brownlow C, McMurray I, et al. SPSS Explained. London: Routledge, 2004.

21. West D, Park J, Pomeroy JR, et al. Concept mapping assessment in medical education: a comparison of two scoring systems. Med Educ 2002;36:820-6.

22. Daley B, Torre D. Concept maps in medical education: an analytical literature review Med Educ 2010;44:440-8.

23. Kirkpatrick D. Evaluation of training. In: Craig R, Bittel L, eds. Training and Development Handbook. New York: McGraw Hill, 1967.

24. Carpenter J. Evaluating Outcomes in Social Work Education. London: Social Care Institute for Excellence, 2005

25. Baernstein A, Liss H, Carney P, et al. Trends in study methods used in undergraduate medical education research, 1969-2007. JAMA 2007;298:1038-45.

26. Hay $\mathbf{D}$. Using concept maps to measure deep, surface and non-learning outcomes Stud High Educ 2007:32:39-57.

27. Gul R, Boman J. Concept mapping: a strategy for teaching and evaluation in nursing education. Nurse Educ Pract 2006;6:199-206.

28. Pinkney L, Penhale B, Manthorpe J, et al. Voices from the frontline: social work practitioners' perceptions of multi-agency working in adult protection in England and Wales. J Adult Protect 2008;10:12-24.

29. Perkins N, Penhale B, Reid D, et al. Partnership means protection? Perceptions of the effectiveness of multi-agency working and the regulatory framework within adult protection in England and Wales. J Adult Protect 2007:9:9-23.

30. Braye S, Preston-Shoot M. Practising Social Work Law. 3rd edn. Basingstoke: Palgrave Macmillan, 2009

31. Goldie J, Schwartz L, McConnachie A, et al. Students' attitudes and potential behaviour with regard to whistle blowing as they pass through a modern medical curriculum. Med Educ 2003;37:368-75. 